\title{
Lo que dicen los proyectos de grado acerca de la investigación formativa en la educación artística ${ }^{1}$
}

\section{What graduation projects say about formative research in artistic education}

Fecha de recepción: 28 de marzo de 2008

Fecha de aceptación: 14 de julio de 2008

Pedro Pablo Gómez ${ }^{2}$, Angélica González ${ }^{3}$, Carolina Acosta ${ }^{4}$

\section{Resumen}

En este artículo se presentan algunos de los resultados del Proyecto de investigación Análisis de cien trabajos de grado del Proyecto Curricular de Artes Plásticas y Visuales de la Facultad de Artes ASAB, realizado entre 2004 y 2006. El proyecto toma como punto de partida la hipótesis que afirma la existencia de actividades investigativas propias del campo del arte, las cuales son susceptibles de ser reconocidas a partir del análisis de los proyectos de grado. De acuerdo con lo anterior, se afirma que la investigación formativa se da en la formación artística y que ésta se objetiva en diferentes productos; uno de ellos, quizá el más importante, los trabajos de grado. Pero no basta con saber que la investigación artística existe, se trata de conocer en qué consiste este tipo de investigación, cuáles son sus cualidades, sus debilidades, sus contingencias, y sobre todo su valor para la proyección de las prácticas investigativas y creativas de la comunidad artística.

\section{Palabras clave}

Investigación formativa, prácticas artísticas, textualidad, interpretación, arte.

\begin{abstract}
Some of the results of the investigation are presented in this article, from the project "Analysis of a hundred works of grade of the Curricular Project of Plastic Visual Arts" of the College of Arts ASAB, carried out between 2004 and 2006. The project takes as starting point the hypothesis that affirms the existence of investigative and characteristic activities of the field of art, which are susceptible of being recognized through the analysis of the grade projects. In accordance to what has been said, it is affirmed that the
\end{abstract}

1 Artículo resultado del proyecto de investigación: Análisis de cien trabajos de grado del Proyecto Curricular de Artes Plásticas y Visuales, de la Facultad de Artes ASAB, financiado por el Centro de Investigaciones Cientificas CIDC de la Universidad Distrital Francisco José de Caldas.

2 Es maestro en Bellas Artes de la Universidad Nacional de Colombia, magíster en filosofía de la Pontificia Universidad Javeriana; docente de la Facultad de Artes ASAB, de la Universidad Distrital Francisco José de Caldas. Actualmente, es el coordinador de investigación de la Facultad de Artes ASAB y director del grupo institucional de investigación POIESIS XXI.

3 Maestra en artes plásticas de la Universidad Distrital Francisco José de Caldas, se encuentra realizando el magíster en filosofía de la Pontificia Universidad Javeriana; docente de la Facultad de Artes ASAB, de la Universidad Distrital Francisco José de Caldas.

4 Estudiante de noveno semestre de artes plásticas y visuales de la Universidad Distrital Francisco José de Caldas. Miembro del grupo de investigación POIESIS XXI. 
formative investigation is given in the artistic formation and it turns into different products; one of them, maybe the most important, the grade works. But it is not enough with knowing that the artistic investigation exists, it's necessary to know on what it consists this of type investigation, which qualities has, their weaknesses, their contingencies, and mainly its value for the projection of the investigative and creative practices of the artistic community.

\section{Key Words}

Formative investigation, artistic practices, written works, interpretation, art.

\section{Caracterización del proyecto de grado}

Los programas de formación artística tienen como requisito de graduación varios tipos de trabajos o proyectos, entre los cuales la modalidad de proyecto de grado en creación tiene un lugar preponderante respecto de otras modalidades como las pasantías, los cursos especiales o las prácticas. Así como el egresado, o nuevo profesional de un área, puede considerarse como el principal logro de los programas de formación, la realización de un trabajo de grado de calidad puede ser considerada como la actividad más importante de alguien que aspira a graduarse como profesional en el campo del arte.

El trabajo de grado es tanto una asignatura del plan de estudios como una práctica artística que da cuenta de un saber específico. En primer lugar, como asignatura ${ }^{5}$, el trabajo de grado posee unas características particulares que lo definen como uno de los resultados más importantes del proyecto de formación. En consecuencia, se espera que el trabajo

5 En nuestro caso particular, y de acuerdo con el Estatuto estudiantil de la Universidad Distrital, el proyecto de grado es una asignatura del currículo que es requisito para optar a un título universitario . El trabajo de grado puede realizarse en forma de pasantía, relacionada con su futura profesión en instituciones públicas o privadas cuya reglamentación corresponde al Consejo Académico de la universidad. Desde 1995 se tiene registro de trabajos de grado de Artes Plásticas y Visuales. de grado dé cuenta de las competencias ${ }^{6}$ adquiridas por el estudiante a lo largo de su proceso de formación: competencias interpretativas, argumentativas, creativas, tecnológicas, entre otras. En segundo lugar, con muy pocas excepciones, los trabajos de grado de Artes Plásticas y Visuales están constituidos por un trabajo de creación con su respectivo texto de sustentación teórica. El trabajo plástico y el texto teórico son dos aspectos fundamentales para la constitución de una unidad teórico-práctica que manifiesta de manera sensible la objetivación de un saber artístico. En consecuencia, un análisis completo de una práctica artística de esta naturaleza deberá tener en cuenta la actividad teórica y la realización plástica del proyecto. Sin embargo, para el caso que nos ocupa, nuestras fuentes se reducen a las memorias ${ }^{7}$ que existen de cada uno de los trabajos de grado, las cuales no tienen un carácter homogéneo, debido en parte a que la concepción de lo que es un proyecto de grado en artes está mediada por la visión particular del estudiante y su asesor. Además, dadas las dinámicas de las prácticas artísticas, la concepción de lo que es un trabajo de grado en artes está en permanente discusión y, de hecho, en permanente transformación. A esta discusión pretende aportar elementos útiles este artículo.

Un proyecto de grado, antes que concebirse como obra de arte, se entiende como una práctica artística o como un conjunto de prácticas que, aunque pueden llegar a ser consideradas como obras de arte,

6 Entendemos las competencias como el conjunto de conocimientos, saberes-prácticas, destrezas, habilidades, intencionalidades y conductas que el proyecto curricular pone en juego para alcanzar la formación en la plástica visual. En este contexto, la competencia es una construcción, resultante de la combinación de recursos, que se hace manifiesta al abordar una situación problemática y que por lo tanto implica la movilización, renovación y cucstionamiento del saber. Teniendo en cuenta la movilidad misma del campo artístico, de sus saberes, concepciones y prácticas las siguientes son las competencias que guían el proceso formativo en el proyecto curricular de Artes Plásticas y Visuales

7 Utilizamos el término memorias para hacer referencia a todos aquellos insumos del Proyecto de Grado que el estudiante aporta a los archivos de la Universidad. La memoria de cada trabajo puede tener un carácter múltiple: puede tratarse sólo de un texto, o este puede estar acompañado de imágenes fotográficas, videos o imágenes digitales presentadas en soportes papel, CD o VHS. 
no lo son a priori en tanto prácticas. Sabemos que, para objetivar una práctica artística, se debe dar un proceso de institucionalización que en términos de James Cliford es un tránsito de esas prácticas hacia ciertas zonas semánticas del sistema arte-cultura, proceso que es realizado mediante la acción de poderosas máquinas institucionales ${ }^{8}$. Las prácticas artísticas tienen lugar sin que deban tener como objetivo necesario la producción de obras de arte. Las prácticas teóricas que se desarrollan en el campo del arte, las prácticas creativas que acompañan el proceso formativo del estudiante y las prácticas de la investigación formativa en artes, son ejemplos de prácticas artísticas que constituyen los trabajos de grado, y que no necesariamente configuran obras de arte. Para llevar un poco más allá estas consideraciones, podríamos decir que el arte no es un objeto, sino una serie de prácticas sociales que son realizadas no solamente por artistas, sino también por una diversidad de agentes que interactúan y constituyen el campo del arte. Además, en esas prácticas se pone en juego una serie de saberes, principios y enfoques que han sido desarrollados a lo largo de la tradición, para constituirse no en meras actividades aisladas de la teoría, ni tampoco en teorías puras, sino en saberes-prácticos por cuyo medio sể construye la significación y la objetivación en el campo del arte.

En síntesis, los trabajos de grado son prácticas artísticas que se objetivan de diferentes maneras, haciéndose susceptibles de análisis como poseedores de una serie de características propias de la investigación formativa en el campo de arte. Si bien estas prácticas también pueden ser abordadas en tanto creaciones que accedan a la calidad de obras de arte, esto no constituye el interés ni el enfoque de este trabajo.

\section{Metodología}

Como punto de partida, de acuerdo con los lineamientos del Consejo Nacional de Acreditación

8 Cf. Cliford, James, Dilemas de la cultura, Editorial Gedisa, Barcelona, 2001, especialmente el capítulo 10 denominado "Sobre la recolección de arte y cultura".
$\mathrm{CNA}^{9}$, los trabajos de grado han sido considerados en la modalidad de la investigación formativa propia de los programas de pregrado. Estos trabajos han sido objeto de análisis mediante un proceso de interpretación. Se ha tomado como punto de referencia la teoría hermenéutica que postula que más allá de un método, la hermenéutica trata de una manera de proceder. Así, uno de los elementos relevantes que aporta la hermenéutica como teoría que soporta el proyecto es precisamente la postura del entender, como una dimensión en donde ciertos saberes se encuentran en relación con otros, pero ninguno puede asumir una superioridad. El entender, dentro de la hermenéutica, ya no queda situado del lado del comprender, es decir, ya no esta limitado al campo de las ciencias, sino que configura la estructura fundamental de la existencia humana. El campo del otro es así dimensionado, no como un objeto para el sujeto, sino como el lugar del intercambio intersubjetivo en donde a la vez se dan las experiencias vivenciales. De acuerdo con Gadamer ${ }^{10}$ todo proceso de comprensión es un proceso de interpretación: el acto interpretativo no se limita a aquello que hacemos sobre los textos o sobre alguna expresión, tampoco al procedimiento por medio del cual se alcanza el sentido correcto de un texto; ese acto se realiza siempre desde una situación específica, que necesita ser guiada desde aquello que se quiere comprender. Esto es lo que posibilita el circulo hermenéutico, que sería esa mediación entre lo comprendido y el que comprende. Adicionalmente, Gadamer llama la atención sobre la fusión de horizontes, como el proceso que resulta en el tiempo de la comprensión y la auto-comprensión.

En el proceso de comprensión de los textos analizados, se abordó un conjunto de prácticas artísticas desde un texto que las documenta. En este sentido,

9. Cf. Restrepo Gómez, Bernardo, Conceptos y Aplicaciones de la Investigación Formativa, y Criterios para Evaluar la Investigación Científica en sentido Estricto, en: www.cna.gov.co/documentos, consultado en enero de 2005.

10 Cf. Gadamer, Hans-Georg, Verdad y Método I, ED. Sígueme, Salamanca, 1993. 
la situación histórica no ha podido ser confrontada a partir de la lectura de obras en sí mismas, dado que en la mayoría de los casos estas prácticas o proyectos finales sólo se presentaron durante un momento específico, por lo general de duración muy corta, condicionando dicha situación a las características del texto. De este modo, la relación entre un texto que dice algo de una obra y la obra misma, que en este caso no es el objeto principal de la interpretación, resulta problemática por cuanto el texto no da y no puede dar cuenta de ella; no puede hacerlo, porque pertenece a otro universo, a otra situación histórica. El texto sobre la obra se aborda desde un proceso de interpretación de algo que no puede ser totalmente abordado. No obstante, en algunos casos hemos llegado a constatar que algunos de estos textos alcanzan un valor literario que, en otras circunstancias, haría posible su consideración como obras en sí mismos.

En términos prácticos, en nuestro modo de proceder dentro del proyecto hemos asumido que el trabajo de interpretación no ha sido una actividad individual sino colectiva. Se construyó un instrumento interpretativo de análisis de cada una de las memorias de los trabajos de grado, elaborado desde nuestros cuestionamientos iniciales y desde las preguntas que se querían formular a los trabajos de grado. Luego de una discusión grupal, se estableció una serie de categorías no excluyentes sobre un trabajo de grado, categorías que permitían agrupar nuestras iniciales inquietudes. Este instrumento plantea las mismas preguntas a cada memoria y proporciona los medios para una sistematización adecuada de los datos obtenidos. Estos datos son, en cierto modo, el resultado de una actividad de diálogo entre el investigador y el autor de trabajo mediante el texto y la memoria de su práctica final de grado. Debido a esto, podemos considerar que el resultado final que se presenta sobre los cien trabajos de grado, es una especie de consenso construido por un grupo de personas en torno a un problema -la investigación formativa-y mediante un procedimiento específico: la interpretación de documentos.

\section{Conceptos clave}

Como resultado del consenso y del análisis conjunto de fuentes primarias y secundarias se han planteado los siguientes conceptos clave entendidos como categorías hermenéuticas que permiten la realización de una especie de mapa conceptual acerca de los intereses epistemológicos y metodológicos de los estudiantes así como de la ubicación de sus prácticas en un contexto social determinado. Esto muestra que los intereses de los estudiantes no sè limitan al plano formal y al ejercicio de competencias disciplinares en los espacios de la Academia sino que van más allá y se insertan en el campo social con sus dimensiones políticas, económicas y culturales. Todo esto permite afirmar el carácter social de formación artística del Proyecto Curricular y, lo que es más importante, el reconocimiento por parte de los estudiantes de la dimensión social de cualquier forma de conocimiento.

Apropiación nominal de conceptos para ver el mundo (12\%)

Dentro del texto no existe una definición de estos conceptos, sino más bien se asume que son comprendidos por todos, lo cual hace que el autor crea que han sido parte natural de nuestra construcción cultural. Por ello, no se preocupa por intentar definirlos; sin embargo, tiene la intención de relacionarlos con otros conceptos y apartando una definición ampliada de los mismos o cuestionando, aquella definición que parece natural. Se realiza un proceso de resignificación y construcción evocativa de estas palabras para ampliar sus propios alcances.

Creación estética desde reflexiones cotidianas $(12 \%)$

Se aborda desde una postura subjetiva la relación con los objetos más cercanos o con las vivencias diarias. 
El cuerpo como lugar y objeto de prácticas artísticas (10\%)

En este conjunto de trabajos se muestra al cuerpo como el objeto de la práctica a veces desde la noción de cuerpo social o desde la propia individualidad del artista.

Ficciones conceptuales operativas en el marco de un problema $(12 \%)$

En esta configuración, el autor decide proponer un concepto o conceptos que ha inventado para desde esa definición abordar su propuesta. En muchos casos, este concepto traduce la manera como el autor se ubica frente al mundo desde su subjetividad; en otros, resulta de la forma como afronta el mundo, realizando, desde el concepto, una crítica a los condicionamientos sociales. La limitación de la construcción del concepto es que sólo se puede inscribir en el marco del trabajo de grado. Algunos ejemplos de lo anterior, son conceptos tales como entidad básica o productora de voluptosidad.

Reflexión conceptual desde discursos artísticos $(7 \%)$

Se definen conceptos que son propios de los discursos del arte y que han configurado el campo de sus preocupaciones: representación, imitación, belleza, juicio, crítica de arte o gusto. Incluye las distintas teorías del arte que han configurado en occidente aquello que se relaciona con maneras de percibir y reflexiona sobre una producción artística.

Reflexión conceptual desde discursos extra artísticos (7\%)

Se define un concepto $o^{\circ}$ conceptos que permiten al autor abordar el problema desde la definición de una palabra que no ha sido diseñada por el autor, sino que proviene de otras disciplinas tales como la antropología, la sociología o la psicología, entre otras. En el texto, aparecen de manera recurrente diversas interpretaciones de la palabra desde el marco de origen, pero también se establecen relaciones con la construcción de la propuesta plástica. En muchos casos, esta definición constituye un lente a través del cual el autor aborda su campo problémico.

Prácticas artísticas relacionadas con la poesía $(2 \%)$

Se establece una relación dialogal entre la práctica artística y la poesía.

Prácticas artísticas que se asumen como catarsis $(8 \%)$

El autor en el texto deja ver claramente cómo aspira a ser transformado y perturbado de manera tal que de su experiencia resulte un cambio significativo para él, pero también para quien contempla la obra. En muchas de estas prácticas, la acción del propio cuerpo esta presente. Aquí se entiende catarsis desde el enfoque aristotélico: como un acto de purificación; no es solamente interno, sino también físico.

Prácticas artísticas relacionadas con la gestión cultural $(1 \%)$

El autor realiza una práctica de gestión cultural relacionada con una localidad específica y tiene la intención de ser útil para una comunidad específica.

Prácticas artísticas relacionadas con un problema social $(8 \%)$

El autor intenta inscribir su práctica desde una visión ampliada del arte de donde no resulta una obra plástica, sino una determinada acción dentro de la comunidad cultural, que reestructura de manera nueva las dinámicas que se inscriben en el ámbito social o dentro de alguna institución cultural. Este tipo de prácticas se relacionan con el sistema arte y cultura y están encaminadas a cumplir una función social o pedagógica. 
Realización de imágenes para confirmar una teoría (1\%)

Se establece un marco conceptual a través del cual se lee un conjunto de imágenes que confirman una teoría o teorías que provienen de un ámbito distinto a la teoría del arte.

Reflexiones teóricas en torno al arte $y / o$ a su historia (1\%)

Este trabajo resulta más del ámbito teórico y la relación del arte y su historia.

Reflexiones teóricas sobre un problema plástico previo (1\%)

El autor configura, en primera instancia, la imagen, y a partir de ella elabora unos conceptos que resultan operativos para intentar definirla. Implícitamente, en este tipo de procedimiento, se encuentra inscrita la problemática de la relación entre la imagen y el texto. La imagen opera como detonante para la construcción del texto. El texto cuenta a posteriori de la práctica. La justificación de todo el texto resulta, entonces, de la reflexión en torno a la obra.

Reivindicación de ámbitos o prácticas simbólicas (18\%)

El campo de lo simbólico opera como el detonante esencial de la práctica, este campo simbólico en algunos casos enfrenta a la cultura occidental con otras culturas o toma elementos de otras culturas o religiones para realizar y contrastar maneras de ver el universo simbólico.

\section{Planteamientos de problemas}

Cada uno de los proyectos de grado que se analizó muestra los conceptos y planteamientos que el estudiante realiza en el proceso teórico a través del cual el futuro egresado pretende dar cuenta de sus competencias profesionales en relación con problemas rea- les del campo del arte en un contexto particular. La forma auto-reflexiva, crítica y la base problémica de los mencionados planteamientos muestra el carácter investigativo de los trabajos de grado que asumen su realización como la puesta en ejercicio de toda un serie de competencias adquiridas a lo largo del proceso formativo, como herramientas y medios que hacen posible el abordaje de problemáticas concretas de la profesión artística. Ahora bien, en el planteamiento del problema no sólo se hacen evidentes las competencias del estudiante sino también ciertas debilidades del orden conceptual, metodológico y estratégico. En consecuencia, el análisis de cada uno de los proyectos de grado evidencia los contrastes que se dan entre ellos, tanto en lo que tiene que ver con el rigor con el que se asumen algunos de ellos y la laxitud con la que otros se realizan. Todo esto involucra a la comunidad académica, en el sentido en que debe realizar una reflexión en torno a la caracterización y normatividad de sus trabajos de grado, desde la concepción de la actividad de la investigación como una práctica formativa. A manera de ejemplo citamos dos de los planteamientos realizados en los correspondientes trabajos de grado:

Objetos secretos, de Julio Armando Ortiz Tarazona:

La sociedad se ha encargado de dejar a la sombra algunas cosas y personas que no encajan con sus parámetros morales. Sin embargo, esa moral ha mutado a través de la historia y lo que hoy es obsceno, en otras épocas fue considerado como normal y apropiado para el público. El autor parte de estas consideraciones para crear una serie de personajes que representan el control que ejercen organismos e instituciones sociales como el Estado. Sacarlos a la luz, así como sus acciones, evidencia la manipulación de la moral para ejercer dominio sobre los individuos, dejando en entredicho, de tal manera, el concepto de libertad. El autor toma una posición en la que califica de inmorales estas estrategias de control, y así reivindica a los sujetos que forman parte del objeto de la propuesta. Sin embargo, no 
es claro si él mismo valida el comportamiento de estos sujetos y, por consiguiente, parece que la propuesta se aventaja de estos personajes para realizar el comentario que quiere hacerse público en contra de las instituciones criticadas.

Las miserables, de Restrepo John:

El autor toma como punto de partida el dolor como producto de la decepción amorosa y lo relaciona con elementos iconográficos y conceptuales de tipo religioso, como la Pasión y su simbología (particularmente, el corazón sangrante) para proponer un trabajo videográfico basado en tres personajes femeninos que encarnan la vocación hacia el dolor por la ausencia del amado. Se trata de una propuesta que parte de una inquietud, a todas luces personal, acerca del dolor que genera la pérdida del ser amado, y de la vocación hacia el mismo como manera de asumir la existencia. El autor reitera que las miserables, tres personajes femeninos que encarnan esa forma de asumir la existencia a través del dolor, son sus hijas, son producto de su propio dolor. Aunque la idea de investigación queda así convenientemente expuesta, en un lenguaje marcadamente poético, la propuesta, de la cual se sabe que es videográfica, no es suficientemente descrita en el texto y la memoria visual no es tan amplia, completa y detallada como para dar cuenta de la misma. Además, el texto está profusamente ilustrado con imágenes y diseños de los cuales no se sabe si son parte de la propuesta misma, o sólo del texto de memoria como objeto.

Teniendo en cuenta que el trabajo de grado se considera como una unidad que relaciona la teoría y la práctica, que en nuestro caso hemos denominado unidad teórico-plástica, pueden analizarse las fortalezas y debilidades de esa unidad como de cada uno de sus componentes por separado.

\section{Fortalezas y debilidades teórico-plásticas.}

\author{
Fortalèzas teórico-plásticas
}

Las fortalezas encontradas en los trabajos de grado confirman el carácter teórico-práctico de los mismos, que en su realización deben resolver de una manera coherente, en correspondencia con el problema abordado, la relación entre la teoría y la práctica de producción plástica y/o visual correspondiente. Sabemos que es allí donde se presenta una clara dificultad a la hora de abordar el papel de la reflexión teórica con respecto a las propias prácticas del estudiante en el contexto de la sociedad y el mundo del arte y la cultura, en donde se inscribe tanto su trabajo académico de grado como su horizonte profesional.

La función de la teoría en un trabajo de grado no se resuelve al reducirla a una exigencia académica de producción de un texto frente al cual puede esgrimirse toda una serie de excusas. Una de ellas, y quizá la más peligrosa, es la concepción que reduce el arte a una serie de prácticas expresivas de la "libre subjetividad", que en tanto tal no tiene ni la necesidad ni la obligación de dar cuenta de sí misma ni de sus constructos, debido a que tanto ella como aquellos son concebidos como inefables. Otra, quizá derivada de la anterior, es la que deja en manos de terceros (críticos, historiadores o comentaristas de arte) la función argumentativa del artista.

En contraste con lo anterior, la coherencia entre la propuesta plástica y la sustentación teórica que' muestran el $38 \%$ de los trabajos de grado analizados, es significativa en tanto que esa coherencia no es el resultado del seguimiento de modelos de realización de imágenes y de elaboración de textos, sino de la capacidad de encontrar una forma adecuada de materialización de la teoría en lo concerniente a un problema planteado. En algunos casos, llama la atención que los estudiantes llegan, incluso, a crear conceptos operativos para la realización de su trabajo. 
Cuadro 1. Comparación entre fortalezas y debilidades

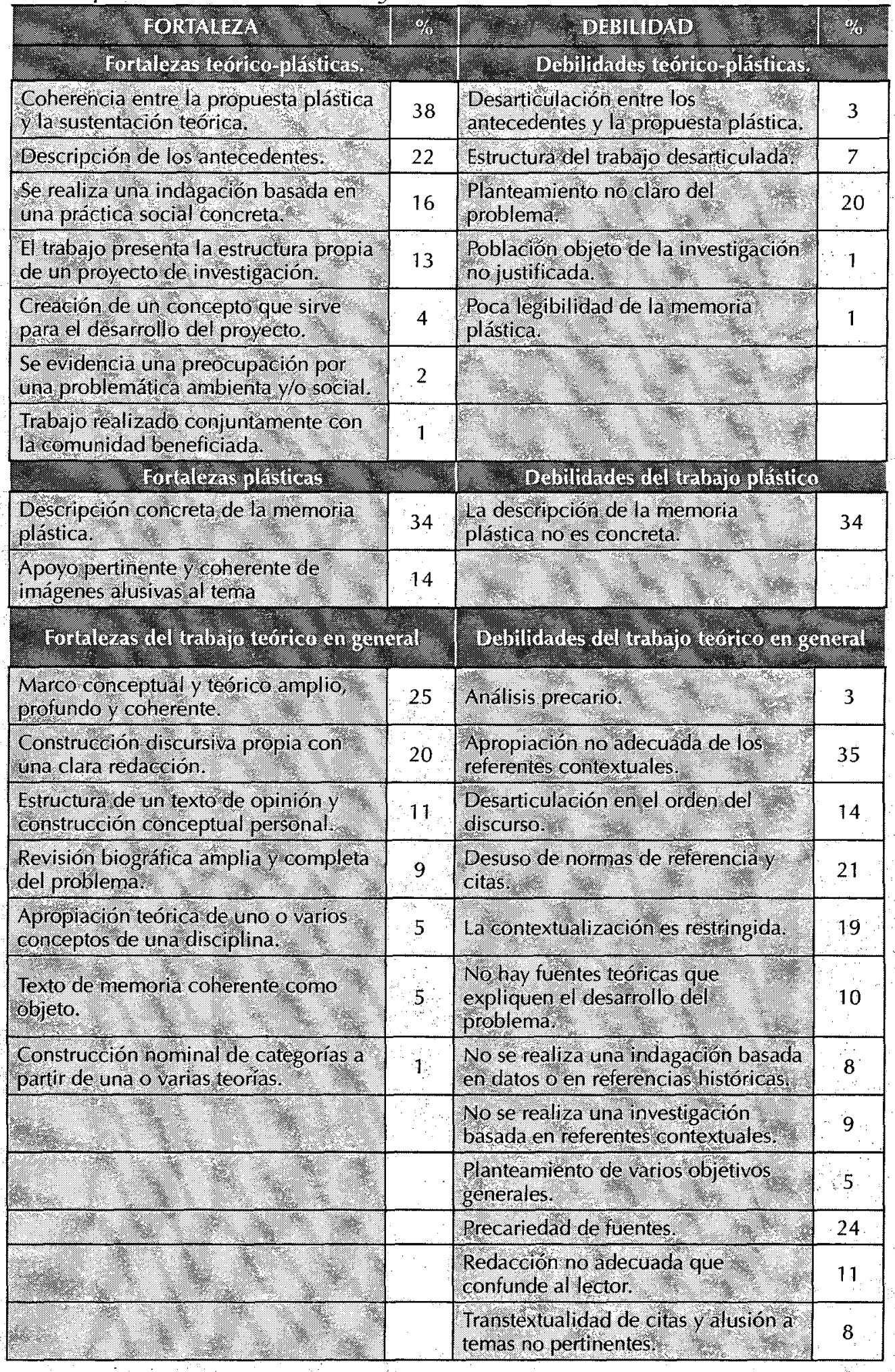


Por otra parte, si anteriormente se había señalado que el $67 \%$ de los trabajos presenta antecedentes del problema planteado, también resulta relevante que 22 proyectos muestren como una fortaleza este aspecto, lo cual quiere decir, entre otras cosas, que la comprensión de la tradición y el propio proceso formativo del estudiante, así como la historia de la cultura y el arte, son relevantes para el planteamiento de problemas actuales; esa comprensión se manifiesta, de manera directa, en los logros generales del proyecto.

Además, 16 proyectos de grado muestran como fortaleza la preocupación por realizar trabajos que tengan que ver con problemáticas sociales concretas. Esto da cuenta del interés comunitario del estudiante y de la inserción de sus prácticas en ámbitos en los que sus planteamientos, discursos y manifestaciones plásticas van a adquirir un valor político en relación con otras prácticas individuales y disciplinares que, sin dejar de pertenecer a su campo específico, se ubican en zonas de intercambio simbólico. Es en estas zonas donde se construyen subjetividades colectivas y se problematiza las categorías de lo público y lo privado.

Por último, se encontró que 13 trabajos de grado presentan la estructura de un proyecto de investigación. Esto no quiere decir que sigan modelos propios de la ciencia y de sus formatos oficiales de presentación y evaluación, sino que plantean su proyecto como problema, y que para abordarlo y resolverlo plásticamente ponen en marcha estrategias, metodologías, conocimientos y competencias adquiridas, con una actitud abierta y desprejuiciada frente al objeto de indagación, atendiendo siempre en el proceso a las observaciones del tutor, a las de los propios colegas y a las de otros profesionales del campo del arte.

\section{Debilidades teórico-plásticas}

Si tenemos en cuenta que la hipótesis de la que parte nuestro trabajo afirma que en la formación artística tiene lugar una forma de investigación, la investigación formativa, cuando no hay un problema claramente planteado el proceso de interpretación y evaluación del trabajo de grado se hace muy difícil. En este sentido, el hecho que un $20 \%$ de los trabajos realizados no presenten un claro planteamiento del problema nos lleva a pensar en una falla fundamental en la concepción de la investigación artística y, a su vez, en la metodología de esa indagación. Si no hay un problema por resolver, que sea del interés del estudiante y en cuya formulación se pongan en acción toda una serie de competencias adquiridas a lo largo de su proceso formativo, desde la perspectiva de un ejercicio profesional, la finalidad del trabajo de grado se reduce a un proceso de validación académica en el que entran a jugar otros factores que, a juicio de los jurados, garantizarían el futuro desempeño profesional del estudiante. La validación del trabajo por las cualidades plásticas del mismo y la posibilidad de una sustentación oral en la que se demuestre, contrario a lo que deje ver el texto, que efectivamente sí existe un problema planteado, podrían ser algunas de las alternativas que se han dado en los 20 trabajos de grado mencionados. Sin embargo, la sustitución o disminución de la exigencia del texto, a cambio de una sustentación oral, iría en detrimento de aquella forma de reflexión que sólo se da por medio de la escritura.

La ausencia del planteamiento de un problema está correlacionada con la desarticulación estructural del trabajo: desarticulación entre los antecedentes y la propuesta plástica, entre los objetivos y los medios, entre las partes del texto y entre éste y la práctica, ( 7 . trabajos muestran la mencionada desarticulación). Ahora bien, si la práctica no se articula alrededor de un problema, entonces los elementos del trabajo de grado buscarán otras formas de relación que pueden ser encuentros fortuitos con espacios y medios que eventualmente pueden llegar a funcionar pero que, sin embargo, contradicen el carácter sistemático del arte contemporáneo, acercándose más a concepciones del arte como el ejercicio de la intuición, la inspiración o la genialidad. 


\section{Fortalezas y debilidades del trabajo plástico}

Fortalezas del trabajo plástico.

En este aspecto se destaca el interés de 34 estudiantes por la realización de un registro visual del proceso del trabajo de grado así como de su montaje y presentación ante los jurados y la comunidad académica del mismo, generalmente en un lugar apropiado cuya gestión, en muchos casos, corre por cuenta del estudiante. De esta manera las imágenes se complementan con el texto haciendo posible un análisis adecuado de la totalidad del proyecto y una valoración justa en lo que a investigación formativa se refiere. Además, las imágenes que presentan estos trabajos no se reducen a la presentación visual de su práctica y su concreción plástica sino que muchas veces se adjuntan imágenes que dan cuenta de cómo otros artistas del contexto nacional e internacional han abordado problemáticas similares. En este aspecto, 14 trabajos muestran una fortaléza evidente.

\section{Debilidades del trabajo plástico.}

Aunque nuestro proyecto no pretende realizar análisis ni valoraciones estéticas de los trabajos de grado sino en cuanto éstos tienen que ver con la investigación formativa, no podemos dejar de señalar como una debilidad que en el $34 \%$ de las memorias haya ausencia de imágenes o que éstas no den cuenta del proceso de realización del trabajo de grado ni de su presentación final. Con esto, se hace muy difícil pensar el la posibilidad de un futuro análisis formal, teórico y estético del conjunto de los trabajos de grado.

\section{Fortalezas y Debilidades del trabajo teórico en general}

Fortalezas que tienen que ver con el trabajo teórico en general

La gama de fortalezas encontradas en los diferentes proyectos de grado ofrece elementos objetivos para

CENTRO DE INVESTIGACIONES Y DESARROLLO CIENTÍFICO el planteamiento de lo que podrían ser los referentes de un trabajo de grado de excelencia, que haga visible las competencias interpretativas, argumentativas, propositivas y creativas propias de un profesional del campo del arte. El 25\% de los trabajos analizados se ocupa de la realización de un marco teórico adecuado y con suficiente profundidad; esto da cuenta del interés y de la capacidad crítica y reflexiva de los estudiantes frente al campo amplio del arte $y$, en lo particular, frente a sus propias prácticas profesionales. Además, en la construcción discursiva y en la redacción sobresalen 20 trabajos en los que es evidente el interés por el lector. Muy probablemente, los autores de estos textos se han dado a la tarea de revisar varias veces sus borradores y han realizado ajustes, previa lectura de otra persona que ha emitido comentarios al respecto, pues es claro que una versión textual bien redactada y articulada no se logra de una sola vez. En once de los trabajos, además, se puede diferenciar claramente la opinión personal del autor frente al pensamiento de otros autores, así como del recurso a las citas textuales cortas y extensas; todo ello, siguiendo la normatividad técnica vigente respecto a la presentación de trabajos escritos.

Por su parte, el $9 \%$ de los trabajos de grado presenta una revisión bibliográfica amplia y completa acerca del problema abordado. Esa bibliografía incluye tanto textos clásicos como títulos actualizados de autores que desde diversas perspectivas pueden ayudar en la construcción de un discurso sobre prácticas artísticas particulares, previa adecuada apropiación de sus planteamientos. Finalmente, el $5 \%$ de los textos muestran un interés muy claro en la presentación misma del escrito, es decir, hay una preocupación por la calidad "editorial" del mismo: la densidad, las relaciones entre texto e imagen, la elaboración de una portada, el tipo y el tamaño de las fuentes y la diagramación, entre otras características. Lo anterior es coherente con la puesta en marcha de las competencias del estudiante de artes plásticas y visuales en lo que tiene que ver con las relaciones de complementariedad que pueden darse entre texto e 
imagen y, de manera particular, con la intención de otorgarle un carácter objetual y plástico a la memoria de su trabajo de grado.

\section{Debilidades que tienen que ver con el trabajo teórico en general.}

Las debilidades que hacen referencia al trabajo teórico tienen que ver con dos aspectos fundamentales: el contenido teórico de la propuesta, por una parte, y los aspectos formales de la misma, por la otra; ambos igualmente importantes si se trata de una práctica profesional.

Si habíamos destacado el planteamiento de problemas en el campo del arte como la base para la realización de una práctica investigativa, la cual hemos denominado investigación formativa, también en evidente que las debilidades respecto al planteamiento del problema y de objetivos generales y específicos, no pueden pasar desapercibidas en una práctica formativa. Cinco trabajos de grado presentan varios objetivos generales, lo cual dificulta enormemente tanto el proceso de autorreflexión del estudiante en lo relativo a su propio trabajo, como la evaluación por parte de los jurados $y$, posteriormente, un análisis de la memoria del trabajo de grado como en nuestro caso. En el planteamiento de varios objetivos generales no se da prioridad a ninguna de las metas propuestas para su consecución en un determinado período de tiempo; por el contrario, esto puede desencadenar una simultaneidad de acciones que en vez de generar relaciones de complementariedad, terminan anulándose unas a otras con direccionamientos diversos que reclaman ser tenidos en cuenta como prioritarios. No puede negarse la cantidad de trabajo que implica un proyecto que persigue objetivos de esta índole; sin embargo, ninguno de ellos puede abordarse con profundidad debido a su extensión.

Todo trabajo de investigación, investigacióncreación o creación hace uso de una diversidad de fuentes, primarias y secundarias, de índole teórico, contextual y referencial. Cuál sea es carácter de esas fuentes y el equilibrio entre fuentes primarias y secundarias no puede definirse a priori, debido a que esto lo determina la estructura interna del proyecto. El tema de las fuentes es visible como una debilidad cuando éstas no son las que el planteamiento del problema exige, después de un análisis evaluativo del mismo. El $24 \%$ de los trabajos de grado presenta precariedad de fuentes en general y el $10 \%$ de los textos analizados no da cuenta de fuentes teóricas a través de la cuales se explique el planteamiento y desarrollo del problema. Además, el uso de fuentes exige un análisis de las mismas y una evaluación de correspondencia o no con el problema planteado. Algunas fuentes, a primera vista, pueden parecer adecuadas y de fácil contextualización en un planteamiento plástico, pero a la hora de contrastar el nivel en que han sido apropiadas y analizadas, se hace evidente que no se ha accedido a ellas por falta de análisis. Un ejemplo de ello es el concepto derridiano de deconstrucción ${ }^{11}$, el cual se emplea de manera demasiado superficial en algunos trabajos analizados. Por su parte, tres trabajos de grado muestran, de manera particular, una precariedad marcada en el análisis de las fuentes.

Por otra parte, toda práctica artística está determinada por un contexto particular en el cual tiene lugar y en donde será valorada de manera positiva o negativa por comunidades de la cultura en general y del campo del arte en particular. Lo anterior muestra la importancia de la contextualización, tanto espacial como histórica, de las prácticas artísticas, teniendo en cuenta los lenguajes y códigos del arte contemporáneo. Si esa contextualización no se da, se corre el riesgo de propiciar lecturas e interpretaciones del planteamiento del problema que quedan a expensas del lector, o incluso, de dar lugar a lo que Umberto Eco denomina decodificación aberrante. Debe quedar claro que aquí nos estamos refiriendo al planteamiento teórico de la propuesta de investigación y no a la propuesta plástica, en la que la apertura de sentido se considera como una cualidad

11 Cf, Derrida Jacques, La verdad en pintura, trads, Maria Cecilia González y Dardo Scavino, Buenos Aires, Paidos, 2001. 
de los signos del arte. Treinta y cinco proyectos de grado muestran debilidad en la contextualización del problema planteado; diecinueve de ellos, aunque realizan la contextualización del problema, lo hacen de una manera restringida e incompleta.

Las debilidades de carácter formal en la presentación del texto se tienen en cuenta debido a que éstas presentan aspectos que determinan directamente el contenido del trabajo de grado y no son, como pareciera en un principio, meras arbitrariedades y caprichos institucionales de los cuales se puede hacer uso o no, argumentando en ello el ejercicio de la libertad del artista. En consecuencia, un texto bien estructurado, con una clara redacción, que tenga en cuenta no sólo al lector directo, en la figura del evaluador, sino a un público especializado más amplio, es algo a lo que debería apuntarse desde los proyectos de grado. Catorce trabajos de grado presentan un texto desarticulado en su estructura interna. Además, en once textos la redacción no es adecuada y cofunde al lector debido, en ocasiones, a problemas en el uso de la gramática del español. Por otra parte, en veintiún textos es evidente el desuso de las normas de referencia y cita que dan un carácter sistemático al empleo de las fuentes textuales. Esta ausencia muestra una falta de rigor académico en la preparación y presentación de un texto que es parte fundamental de un trabajo de grado, y no un mero accesorio. Finalmente, en ocho textos se presenta lo que hemos denominado transtextualidad de citas y alusión a temas no pertinentes. La transtextualidad tiene que ver con una especie de transplante de discursos y planteamientos teóricos de otras disciplinas, sin la respectiva recontextualización en el campo del arte; al parecer no se tiene en cuenta que un mismo discurso funciona de manera distinta de acuerdo con el contexto en el que tenga lugar. Así, se deja en manos de la cita una tarea explicativa que, debido al desarraigo de su campo de origen, no funciona en el campo del arte. Unas adecuadas referencias textuales no ahorran la tarea analítica y reflexiva de la que da cuenta un texto que corresponde a un trabajo de

CENTRO DE INVESTIGACIONES Y DESARROLLO CIENTÍFICO grado. En algunos escritos analizados se presenta de manera evidente esta debilidad.

\section{Clases de textos}

La variedad de textos que se encuentra en los trabajos de grado de artes da cuenta de una diversidad de intereses y competencias, lo cual se muestra en detalle en cada uno de los análisis. En este sentido, el acto de escritura no se queda simplemente en la fijación de lo dicho ${ }^{12}$, sino que un texto mira siempre hacia delante, hacia sus posibles lectores, y en este sentido se dirige siempre a otro.

Sabiendo que en nuestro proyecto de formación no existe una normatividad para la presentación de textos, debemos aclarar que la clasificación que se analiza a continuación surge, no tanto de la contrastación con determinados modelos de textos propuestos desde una normatividad institucional o modelos previos dentro de las artes plásticas, sino de una aproximación del texto mismo a las categorías encontradas. No se trata de una medida que se sobrepone en las cosas, sino una especie de metrion, una medida que está en las cosas mismas, en su interior, la cual constituye la justa medida de algo (Gadamer, 1997). En consecuencia, las categorías conceptuales encontradas deben entenderse como surgidas de la lógica interna de una actividad que es susceptible de perfeccionamiento y evaluación crítica.

Además, entendemos que la tesis es un trabajo de grado propio de un doctorado y no propiamente de un pregrado. Ahora bien, cuando se trata de un pregrado, un texto monográfico de investigación puede ser suficiente para optar al título respectivo. Sin embargo, en el proyecto que nos ocupa, en todos los casos el texto se ha presentado como un componente de un trabajo teórico-práctico, pero en ningún caso como el único resultado del trabajo de grado; aunque, como se indicará más adelante,

12 Gadamer, Hans- Georg, Texto e interpretación, en Antología. Hans- Georg Gadamer, op. cit., p. 204. 
algunos de los textos presentados tienen cualidades suficientes para ser considerados el trabajo de grado en sí mismos.

Por otra parte, es notable el interés permanente de los estudiantes por explorar diferentes aspectos de diagramación y diseño para elaboración de sus textos, cuyos logros se hacen manifiestos con diferentes niveles de calidad. En algunos casos, cabe considerar al texto como objeto. A continuación, presentaremos los resultados sobre cada una de las ocho diferentes formas de presentación de textos: informe: $43 \%$; texto libre: $24 \%$; monografía: $13 \%$; compilación teórica: $6 \%$; ensayo $6 \%$; diario: $4 \%$; poesía $3 \%$; guión de video $1 \%$.

\section{Conclusiones}

- De acuerdo con el análisis detallado de cada uno de los proyectos de grado, en lo que respecta a los planteamientos del problema, es evidente la necesidad de asumir dicho planteamiento como el primer paso para abordar un problema de investigación, de investigación-creación o de creación en el campo del arte. Un trabajo de grado requiere de manera ineludible la formulación de problemas, sin la cual, el asunto de la investigación puede disolverse, por la ausencia de un objeto y objetivos claros, en una serie de prácticas inconexas o de ejercicios sin fundamentación y profundización que se reducirín a una simple formalidad. Las prácticas artísticas alrededor de problemas hacen evidente que hay una cercanía con prácticas investigativas y de proyección social, que amplían el horizonte de la formación artística más allá de concepciones del arte que lo reducen a una actividad que depende de la inspiración. Aunque esta puede dar el inicio a una idea, se necesita de una actividad reflexiva, de un proceso riguroso para que la idea se objetive de algún modo como resultado de una practica artística. Cuando se elude el planteamiento del problema se presenta una debilidad de orden conceptual o metodológico.
- Para el contraste entre fortalezas y debilidades se asumió que el trabajo de grado constituye una unidad entre dos componentes fundamentales: la teoría y la práctica. Sin embargo, de manera formal estos dos componentes pueden ser analizados en su relación y a su vez de manera individual (debido a que estamos tratando con prácticas artísticas que en la mayoría de los casos se objetivan como imágenes plásticas se sustituyó la práctica por la plástica). Así, se encontró que hay elementos objetivos que dan cuenta de fortalezas y debilidades que tienen que ver de manera directa con el trabajo en su unidad teórico-plástica, otras corresponden sólo al plano teórico y otras únicamente a la realización plástica.

- De acuerdo con lo anterior, una de los aspectos sobresalientes tiene que ver con la función de la teoría en un trabajo de grado, que no se reduce a una exigencia académica de producción de un texto frente al cual puede esgrimirse toda una serie de excusas. Una de ella y quizá la más peligrosa es la concepción que reduce el arte a una serie prácticas expresivas de la "libre subjetividad", que en tanto tal no tiene ni la necesidad ni la obligación de dar cuenta de sí misma ni de sus objetivaciones, debido a que el arte y sus prácticas son concebidos como inexplicables. Otra, quizá derivada de la anterior, es la que deja en manos de terceros (críticos, historiadores o comentaristas de arte) la función argumentativa del artista. Lo anterior lleva a plantear a la comunidad académica la necesidad de llegar a consensos sobre la consistencia, las modalidades $y$ las exigencias de un trabajo de grado.

- Por otra parte, respecto de las debilidades de los proyectos de grado, el hecho que un $20 \%$ de ellos no presente un claro planteamiento del problema nos lleva a pensar en una falla fundamental en la concepción de la investigación artística y a su vez, en la metodología de esa indagación. Si no hay un problema por resolver, que sea del 
interés del estudiante y en cuya formulación se ponga en acción toda una serie de competencias adquiridas a lo largo de su proceso formativo desde la perspectiva de un ejercicio profesional, la finalidad del trabajo de grado se reduce a un proceso de validación académica en el que entran a jugar otros factores que, a juicio de los evaluadores, garantizarían el futuro desempeño profesional del estudiante. Esto nos lleva a relativizar el carácter positivo que habíamos señalado antes, al constatar la existencia de la investigación formativa en los proyectos de grado, y a plantear la urgencia de procesos de evaluación de fortalezas y debilidades en cada una de las dimensiones de la formación artística del proyecto curricular.

- No obstante lo anterior, no se debe olvidar que una cuarta parte de los trabajos analizados se ocupa de la realización de un marco teórico adecuado y profundo que da cuenta de la capacidad crítica y reflexiva de los estudiantes frente al campo amplio del arte y frente a sus propias prácticas profesionales. Además, hay trabajos sobresalientes en la construcción discursiva y en la redacción, lo que muestra un interés genuino por el lector. En esos trabajos se puede diferenciar claramente la opinión personal del autor del pensamiento de otros autores, haciendo uso correcto de las fuentes, las citas textuales y siguiendo la normatividad técnica vigente respecto a la presentación de trabajos escritos. En consecuencia el trabajo de evaluación general propuesto anteriormente debería insistir en el afianzamiento de aquellas fortalezas que son evidentes y trabajar el la superación de las debilidades identificadas.

- Sabiendo que en nuestro proyecto de formación no existe una normatividad para la presentación de textos, debemos aclarar que la clasificación que presentamos surgió no tanto del contraste con determinados modelos de textos propuestos desde una normatividad institucional o modelos previos dentro de las artes plásticas, sino de una aproximación del texto mismo a las categorías encontradas. Además, la variedad de textos encontrados no debe servir de soporte para una normatividad restrictiva sobre alguna forma ideal de textualidad que pretenda la uniformidad de los trabajos de grado; por el contrario, esa variedad indica la necesidad de afirmar la diversidad de prácticas de escritura, que abren posibilidades para el estudiante y el asesor de optar por un tipo de escritura acorde con el problema y con sus estrategias metodológicas. Cualquiera que sea el tipo de texto elegido, debería ser evaluado con la lógica y el rigor propio de cada forma de escritura; se hace necesario entonces vincularlo con la naturaleza misma del proyecto de grado y que estos dos se encuentren en una relación de complementariedad.

\section{Bibliografía}

Universidad Distrital Francisco José de caldas. Estatuto estudiantil. Acuerdo No. 027 de diciembre 23 de 1993.

Calvo Martínez, T,; et al, (1991). Paul Ricoeur: los caminos de la interpretación, Barcelona, Anthropos.

Clifford, J. (2001). Dilemas de la cultura, Barcelona, ED. Gedisa.

Borrero, A. (1985). Conferencia No. XX, del Simposio Permanente sobre la Universidad. Bogotá, Asociación Colombiana de Universidades -ASCUN.

CONNOR S. (2002). Cultura postmoderna, Barcelona, Akal.

ASAB, (2005). Documento institucional de creación de la Facultad de Artes. 
Gadamer, H. (2005) “Lenguaje y música, escuchar y comprender", en: Teoría de la Cultura, compilado por Gerard Schroder y Helga Breuninger, México, Fondo de Cultura Económica. ,(1993). Verdad y Método I, Salamanca, ED. Sígueme.

(1992). Verdad y Método II, Salamanca, ED. Sígueme. , (2001) Antología. Hans- Georg Gadamer, Salamanca, ED. Sígueme.

Grondrin, J. (1999). Introducción a la hermenéutica filosófica, s.l., ED. Herder
Larrañaga, J. (2001), Instalaciones, s.l., ED. Arte Hoy.

Restrepo Gómez, B. (marzo de 2006). Conceptos $y$ aplicaciones de la investigación formativa, $y$ criterios para evaluar la investigación científica en sentido estricto, en: www.cna.gov.co/ documentos.

Souriau, E. (1998). Diccionario Akal de Estética, Madrid, ed. Akal.

V.V.A.A, (2000) Arte del Siglo XX, ED. Taschen. 